\title{
NILAI PENDIDIKAN KARAKTER FILM RUDY HABIBIE SUTRADARA HANUNG BRAMANTYO
}

\author{
Rita Nilawijaya \\ Program Studi Pendidikan Bahasa dan Sastra Indonesia \\ FKIP, Universitas Baturaja \\ Pos-el: nilawijaya.rita@gmail.com
}

\begin{abstract}
Abstrak
Tujuan penelitian ini adalah untuk menganalisis nilai pendidikan karakter dalam film Rudy Habibie sutradara Hanung Bramantyo. Metode yang digunakan dalam penelitian ini adalah metode deskriptif. Pendekatan yang digunakan adalah pendekatan sosiologi sastra. Peneliti menggunakan film Rudy Habibie yang disutradarai oleh Hanung Bramantyo sebagai sumber data yang digunakan. Teknik penelitian yang digunakan adalah teknik pengumpulan data dengan menggunakan teknik deskriptif dan teknik penganalisisan data dengan menggunakan teknik analisis isi. Hasil penelitian dan pembahasan yang telah dilakukan, terdapat nilai pendidikan karakter di dalam film Rudy Habibie meliputi nilai religius, kerja keras, peduli sosial, jujur, kreatif, gemar membaca, demokratis, tanggung jawab, dan cinta tanah air, dan dapat dijadikan pedoman bagi guru maupun peserta didik untuk bersikap yang baik dalam menjalankan kehidupan sehari-hari berdasarkan nilai-nilai kebaikan yang ada.

Kata-kata kunci: Nilai pendidikan karakter, film, sosiologi sastra.
\end{abstract}

\begin{abstract}
The purpose of this study was to analyze the value of character education in the film Rudy Habibie directed by Hanung Bramantyo. The method used in this research is descriptive method. The approach used is the sociology of literature approach. The researcher used the Rudy Habibie film, directed by Hanung Bramantyo as the source of the data used. The research technique used is data collection techniques using descriptive techniques and data analyzing techniques using content analysis techniques. The results of the research and discussion that have been carried out, there are values of character education in Rudy Habibie's films which include religious values, hard work, social care, honesty, creativity, love of reading, democracy, responsibility, and love for the country, and can be used as guidelines for teachers. as well as students to behave well in carrying out daily life based on existing good values.

Key words: The value of character education, film, sociology of literature.
\end{abstract}




\section{PENDAHULUAN}

Karya Sastra di Indonesia sangat beragam salah satunya adalah novel. Novel adalah karya sastra imajinasi pengarang. Pengarang menawarkan sebuah keadaan atau konflik yang disesuaikan dengan realita hidup seseorang, baik konflik hidup yang dialami oleh pengarang itu sendiri maupun konflik yang dialami oleh orang lain (Nilawijaya Rita, 2018 dalam Jurnal KIBASP Vol. 2 No.1 hal 11-23).

Novel merupakan sebuah struktur organise yang kompleks, unik, dan mengungkapkan segala sesuatu secara tidak lansgung. Tujuan utama analisis kesastraan, fiksi, puisi, ataupun yang lain adalah untuk memahami secara lebih baik karya sastra yang bersangkutan. Aspek-aspek pokok kritik sastra adalah analisis, interpretasi (penafsiran), dan evaluasi atau penilaian. Karya sastra merupakan sebuah struktur yang kompleks, maka untuk memahaminya perlu adanya analisis, yaitu penguraian terhadap bagian-bagian atau unsurunsurnya. Sesungguhnya, analisis itu merupakan salah satu sarana penafsiran atau interpretasi (Pradopo, 2008: 93). sastra bukan hanya semata-mata merupakan wujud gejala individual tetapi merupakan gejala sosial. (Nilawijaya, Rita dan Inawati, 2020 dalam Jurrnal Ilmiah Bina Bahasa jilid 13(02) hal 23-32, 2020 Online Universitas Bina Dharma).
Pendidikan karakter adalah sebuah sistem yang menanamkan nilai-nilai karakter pada peserta didik, yang mengandung komponen pengetahuan, kesadaran individu, tekad, serta adanya kemauan dan tindakan untuk melaksanakan nilai-nilai baik terhadap Tuhan Yang Maha Esa, diri sendiri, sesama manusia, lingkungan, maupun bangsa, sehingga akan terwujud insan kamil (Aunillah 2011:18).

Wujud pendidikan karakter antara lain nilai moral, agama, nilai moral kepribadian, dan nilai moral sosial (Soeparwoto, 2004) begitu pula dengan Suseno yang mengkategorikan nilai moral dengan istilah etika wahyu, etika peraturan, dan etika situasi (Nilawijaya, Rita dan Inawati, 2020 dalam Jurnal Ilmiah kependidikan STKIP PGRI Bandar Lampung vol.13/No.1/2020/Hal 63-78). Dalam hasil penelitian tersebut menunjukkan bahwa nilai moral agama tokoh utama baik dengan persentase $9,3 \%$, begitupula dengan nilai moral kepribadian dengan persentase 9,0\%, dan nilai moral sosialnya dengan persentase 9,6\%. Nilai moral tokoh utama dapat menjadi teladan dan pelajaran bagi mahasiswa sehingga dapat membentuk karakter yang kuat dalam nilai moral beragama, nilai moral kepribadian, dan nilai moral sosial.

Sejatinya, pengajaran sastra mampu dijadikan sebagai tempat dalam penanaman 
nilai-nilai seperti moral yang baik, agama yang kuat, sopan santun dan lain sebagainya karena hal ini juga banyak ditemukan dalam sebuah karya sastra.

Karya sastra merupakan sebuah karya imajinatif yang dilandasi kesadaran dari segi kreativitas sebagai karya seni. Sebagai hasil imajinatif, selain berfungsi sebagai hiburan yang menyenangkan, karya sastra juga berguna untuk menambah pengalaman batin bagi pembacanya. Berbicara tentang karya sastra, akan ada kaitannya dengan seni. Bidang kesenian merupakan bidang sastra yang mengacu pada sebuah pertunjukan kesenian (Kasnadi dan Sutejo, 2010:58).

Salah satu bidang kesenian adalah film. Film termasuk karya seni yang mampu menyampaikan informasi dan pesan dengan cara yang kreatif. Selain dapat menghibur, film juga dapat dijadikan sarana penanaman nilai-nilai yang harus dimiliki oleh setiap orang khususnya dilingkungan pendidikan. Dalam hal ini peneliti memilih film Rudy Habibie yang disutradarai oleh Hanung Bramantyo sebagai bahan penelitian.

Film Rudy Habibie mengangkat kisah perjuangan masa muda tokoh Presiden Republik Indonesia ketiga Bacharuddin Jusuf Habibie yang memiliki nama kecil Rudy. Sebuah film yang diadaptasi dari buku berjudul Rudy: Kisah Masa Muda Sang Visioner karangan penulis skenario Ginatri S. Noer, yang mengisahkan saat
Habibie menuntut ilmu teknologi penerbangan di Jerman pada era tahun 1950-an. Semasa kuliah di Jerman bersama beberapa rekan sesama pelajar Indonesia, Rudy bercita-cita merancang pesawat terbang. Film pertama tokoh Bacharudin Jusuf Habibie dengan judul Habibie dan Ainun yang sebelumnya telah sukses, hal ini menunjukkan betapa banyak peminat dari kisah perjuangan tokoh B. J Habibie yang mampu menjadi inspirator, begitu juga dengan film keduanya ini yang berjudul Rudy Habibie, gambaran sifat-sifat atau karakter dari para pemainnya dalam film tersebut dapat dijadikan sebagai penanaman nilai pendidikan karakter terhadap diri sendiri maupun orang lain. Dengan demikian siswa dapat meniru perilaku baik yang dicontohkan oleh tokoh-tokoh yang ada dalam cerita agar lebih baik dalam bersikap dan berperilaku sesuai dengan norma yang ada dalam kehidupan masyarakat. Berdasarkan paparan di atas, peneliti menyadari betapa pentingnya penanaman nilai pendidikan karakter dalam sebuah karya sastra, dengan demikian peneliti tertarik melakukan penelitian dengan judul nilai pendidikan karakter dalam film Rudy Habibie sutradara Hanung Bramantyo.

Tujuan Penelitian untuk mendeskripsikan nilai pendidikan karakter yang terdapat dalam film Rudy Habibie 
sutradara Hanung Bramantyo. Penelitian ini diharapkan dapat bermanfaat secara teoretis dan praktis. Secara teoretis, hasil penelitian ini diharapkan dapat memberikan gambaran mengenai nilai pendidikan karakter dalam film Rudy Habibie sutradara Hanung Bramantyo. Secara praktis, penelitian ini dapat memberikan manfaat bagi guru, pembaca, serta bagi peneliti lain.

\section{METODE PENELITIAN}

Penelitian ini menggunakan dua sumber data yaitu data primer dan data sekunder. Data primer penelitian ini adalah film berjudul Rudy Habibie yang disutradarai oleh Hanung Bramantyo dan diproduksi oleh manoj Punjabi Present. Film tersebut berdurasi 135 Menit, dengan sampul kaset berwarna putih serta terdapat gambar aktor ternama Reza Rahardian yang berperan sebagai Rudy Habibie dalam film tersebut. Sejalan dengan hal tersebut, Arikunto (2013:22) mengemukakan bahwa data sekunder adalah data yang diperoleh dari dokumen-dokumen grafis (tabel, catatan, notulen rapat, SMS, dan lain-lain), foto-foto, film, rekaman video, benda benda, dan lain-lain yang dapat memperkaya data primer. Data sekunder dalam penelitian ini adalah skripsi, bukubuku sastra, dan buku-buku lain yang relevan dengan penelitian ini.
Metode penelitian dalam penelitian ini adalah menggunakan metode deskriptif. Pendekatan yang digunakan peneliti dalam penelitian ini adalah pendekatan sosiologis. Langkah kerjanya sebagai berikut:

1) Pembicaraan yang paling dulu dilakukan adalah mengenai sosok pengarang, segi sosial yang ada di dalam karya, segi pembaca atau khalayak pendukung dibicarakan setelah pengarang.

2) Hal penting yang dibahas tentang pengarang adalah tentang falsafah yang dianutnya, idiologi politiknya, status sosialnya, pendidikannya, sosialisasinya, dan kehidupan keagamaannya.

3) Telaah aspek intrinsik karya sastra dikaitkan dengan kepentingan masyarakat serta misi sastra dalam meningkatkan taraf kehidupan. Tema harus dilihat dalam kaitan kepentingan masyarakat banyak.

4) Resepsi, kesan, dan sambutan masyarakat terhadap karya sastra juga perlu dianalisis. Karya sastra yang dinilai baik, adalah karya sastra yang secara langsung atau tidak digunakan masyarakat sebagai pegangan.

5) Di samping kesan pembaca atau sambutan pembaca mendapat kajian, juga dikaji dan diperhatikan masalah pengaruh karya sastra tersebut bagi pembaca dan juga bagi penulis. Apa efek positif yang mereka terima. 
6) Hal lain yang harus mendapat penilaian dan kajian adalah tata nilai, etika, budaya, falsafah yang ada dalam karya sastra. Penilaian mengenai ini dilakukan sambil menilai aspek indoktrinasi, dogma, didaktik, dan protes sosial yang terdapat di dalamnya

Teknik pengumpulan data dalam penelitian ini adalah dengan menggunakan teknik deskripsi. Langkah-langkah yang akan dilakukan peneliti dalam pengumpulan data ini sebagai berikut.

a. Mengumpulkan literatur berupa catatan, buku-buku, dan sumber lain yang mendukung permasalahan yang diteliti.

b. Menonton film Rudy Habibie sutradara Hanung Bramantyo dengan seksama untuk memperoleh gambaran menyeluruh tentang isi ceritanya.

c. Menandai setiap scene dalam film Rudy Habibie sutradara Hanung Bramantyo yang terdapat nilai pendidikan karakter.

Teknik yang digunakan dalam menganalisis data adalah teknik analisis isi. Menurut Ratna (2012:48) mengungkapkan bahwa teknik analisis isi adalah pesan pesan dengan sendirinya sesuai dengan hakikat sastra, dalam metode analisis ini terdiri dari dua macam, yaitu isi laten dan isi komunikasi. Dimana isi laten adalah isi yang terkandung dalam dokumen atau naskah. Sedangkan isi komunikasi adalah pesan yang terkandung sebagai akibat komunikasi. Adapun langkahlangkah yang dilakukan dalam menganalisis film Rudy Habibie sutradara Hanung Bramantyo sebagai berikut.

a. Menonton film Rudy Habibie sutradara

b. Mengidentifikasi tokoh

c. Menganalisis tokoh dan penokohan

d. Mengklasifikasikan setiap scene berdasarkan nilai pendidikan karakter

e. Menganalisis nilai pendidikan karakter

f. Membuat simpulan.

\section{HASIL DAN PEMBAHASAN}

Nilai Pendidikan Karakter dalam Film Rudy Habibie Sutradara Hanung Bramantyo Berdasarkan hasil analisis, terdapat sembilan nilai pendidikan karakter dalam film Rudy Habibie yang disutradarai oleh Hanung Bramantyo. Adapun nilai-nilai tersebut yaitu nilai religius, kerja keras, peduli sosial, jujur, kreatif, gemar membaca, demokratis, tanggung jawab, dan cinta tanah air. Adapun penjelasannya sebagai berikut.

\section{a. Religius}

Tokoh Rudy memiliki karakter religius, itu terlihat dalam beberapa adegan berikut: "Ya saya muslim, saya tidak memakan babi" (Scene 4, 06:10-06:50). Berdasarkan adegan di atas, terlihat Rudy sangat mematuhi peraturan agama Islam 
yang dianutnya seperti larangan memakan daging babi. Ketika ia sedang memakan sebuah roti berisi daging, kemudian setelah mendengar perkatan pastur Gilbert bahwa itu adalah daging babi, ia kaget dan langsung memuntahkan makanannya. Hal ini merupakan salah satu contoh karakter religius yang harus dimiliki oleh setiap orang khususnya peserta didik. Karakter religius juga dapat terlihat pada adegan berikut. Selain mematuhi larangan yang ada pada ajaran agamanya, Rudy juga termasuk tokoh yang tekun dalam beribadah. Ia melakukan ibadah dimana pun ia berada seperti yang telihat pada kutipan adegan dibawah ini. Ketika di negara Jerman tak ada masjid atau mushola, Rudy tetap melakukan shalat dibawah tangga kampusnya. Seseorang heran melihat Rudy dan memfotonya. Frank: "Sedang apa kamu?" Rudy: "Saya sedang sembahyang" Frank :"Saya Frank" (sambil mengulurkan tangannya) Rudy: "Bacharudin Jusuf Habibie, nama saya Rudy" (Scene 13, 24:14-24:54). Kutipan di atas juga menunjukkan ketekunan yang dilakukan Rudy dalam beribadah. Meski tidak ada masjid, ia tetap melaksanakan kewajibannya sebagai seorang muslim, ia melakukan ibadah di bawah tangga kampusnya.

\section{b. Kerja Keras}

Karakter kerja keras ditemukan dalam film Rudy Habibie, adapun adegan yang menggambarkan karakter tersebut adalah sebagai berikut. Rudy berusaha menyelesaikan tugas kuliahnya dengan membaca berbagai macam buku di perpustakaan, hingga menemukan masalahmasalah yang ia cari. "Aa ini, ini saya kumpulkan dari seluruh koran yang ada di Eropa..." hal ini menunjukkan kerja keras Rudy dalam mengumpulkan berbagai macam surat kabar dan buku-buku untuk menyelesaikan tugas kuliahnya. Sungguh bukan pekerjaan yang mudah, namun dengan penuh kerja keras akhirnya Rudy mampu menyelesaikan persoalan yang diberikan oleh profesor yang mengajarnya. Karakter kerja keras juga terlihat ketika Rudy menyelesaikan pekerjaannya pada adegan berikut. Hingga sore hari Rudy berusaha menyelesaikan pesawat dari kayu buatannya. Tuan Helmer: "Kamu belum pulang?" Rudy:"Ya..” Tuan Helmer: "Boleh saya bantu, lubang area di sini harus sama persis dan lubang yang lainnya juga, ini harus kita uji di luar". Rudy: "Iya.." Akhirnya Rudy berhasil menyelesaikan pesawat buatannya dan menerbangkannya bersama tuan Helmer (Scene 38, 52:4553:00). Pada kutipan di atas, dapat terlihat Rudy yang dengan bersungguh-sungguh menyelesaikan pesawat rakitan buatannya 
sendirian, meskipun yang lain sudah beranjak untuk pulang.

\section{c. Peduli Sosial \\ Dalam film Rudy Habibie terdapat} karakter peduli sosial yang ditunjukkan oleh tokoh yang ada di dalam film tersebut, di antaranya ketika Rudy sedang mencari tempat tinggal bersama pastur Gilbert, ia membantu seseorang membetulkan penghangat ruangan. Pemilik rumah: "Pastur Gilbert, Nyonya Gunther baru saja menelpon saya, kami tidak bisa menampung mahasiswa luar negeri" Pastur Gilbert:"Ya, saya mengerti nyonya, tapi saya mohon sekali, anak ini butuh tempat tinggal" Pemilik rumah: "Maafkan, suami saya sedang repot memperbaiki pemanas ruangan terbarunya". Rudy: "itu penghangat ruangan dengan air panas kan?". Pemilik rumah: "Ya, kamu bisa berbahasa belanda?" Rudy langsung masuk dan berusaha memperbaiki mesin itu, meski awalnya pemilik rumah marah dan melarangnya, namun mereka langsung terdiam karena Rudy berhasil memperbaiki mesin itu, kemudian pemilik rumah itu menawarkan sebuah kamar untuknya (Scene 5, 07:50-10:30). Berdasarkan kutipan di atas, dapat terlihat karakter peduli yang juga dimiliki oleh tokoh Rudy. Karena merasa ia bisa, ia membantu seseorang untuk memperbaiki mesin penghangat ruangan. Meskipun pada awalnya pemilik rumah tidak mempercayai Rudy, namun Rudy berhasil memperbaiki mesin itu, hingga pemilik rumah akhirnya memberikannya sebuah kamar kontrakan untuknya.

d. Jujur

Kejujuran juga salah satu karakter yang baik untuk diterapkan dalam kehidupan sehari-hari, dalam film Rudy Habibie terdapat beberapa adegan yang memperlihatkan karakter tersebut, sebagai berikut. Ketika ibu Tuti marini atau mami memberikan oleh-oleh dari Indonesia untuk teman-teman Rudy, ibu Tuti Marini bertanya tentang Illona kepada Ayu. Ibu Tuti Marini: "Ayuu...Ayu kenal dengan gadis yang ada di foto ini?" (sambil menyodorkan sebuah foto Rudy dan Illona). Ayu: "Emang ada apa tante?" Ibu Tuti Marini: "Wah, ndak apa-apa, tante Cuma kepingin ketemu sebelum tante pulang ke Indonesia minggu depan" Ayu pun memberitahu alamat Illona, dan Ibu Tuti Marini langsung mengunjunginya (Scene 75, 01:41:15-01:41:47). Berdasarkan kutipan adegan di atas, dapat terlihat kejujuran yang dimiliki oleh tokoh Ayu. Ayu kaget ketika maminya Rudy menunjukkan foto Illona dan menanyakan keberadaannya, meskipun ia tidak menyukai Illona karena cemburu, namun Ayu tetap memberitahu alamat rumah Illona kepada 
ibunya Rudy, bahkan ia meminta Sugeng untuk mengantar maminya Rudy ke rumah Illona. Karakter jujur juga dapat terlihat pada kutipan adegan berikut. Ibu Tuti Marini mendatangi rumah Illona dan berbincang dengannya. Ibu Tuti Marini: "Keluarga kami adalah keluarga Islam yang taat, bangsa kami juga sedang susahsusahnya. Rudy harus kembali ke Indonesia, kalau nona benar-benar serius dengan anak saya, apa nona bersedia ikut ke Indonesia dan menjadi Islam? Hmmm, saya harus menyampaikan ini sekarang supaya nanti kedepannya tidak menjadi masalah. Nona tidak perlu menjawabnya sekarang, permisi." Illona: "Tunggu, tidak perlu lama untuk menjawab itu. Saya mencintai Rudy, tapi saya tidak tahu apakah Rudy benar benar mencintai saya. Saya rela pindah agama dan negara untuk Rudy, tapi apakah Rudy pantas menerima pengorbanan saya" (Scene 77, 01:42:20-01:44:09). Karakter jujur juga dimiliki oleh tokoh Illona, ketika ibunya Rudy mendatangi rumahnya dan menanyakan tentang keseriusannya dengan Rudy, bahkan ibunya Rudy juga mengatakan tentang Rudy yang tidak bisa meninggalkan Indonesia. Meski awalnya Illona hanya diam mendengarkan ibunya Rudy berbicara, namun ketika ibunya Rudy akan meninggalkan Rumahnya Illona dengan tegas dan jujur mengakui perasaannya kepada ibunya Rudy dan menjelaskan semua yang ia rasakan terhadap Rudy. Berdasarkan adegan di atas, terlihat pada adegan pertama kejujuran Ayu memberi tahu tentang Illona kepada ibunya Rudy, meskipun ia merasa cemburu melihat foto yang ditunjukkan oleh ibunya Rudy kepadanya. Kemudian adegan kedua, karakter jujur juga dimiliki oleh tokoh Illona, ia mengakui perasaannya terhadap Rudy di depan ibunya Rudy. Karakter jujur memang sangat penting dimiliki oleh setiap orang khususnya peserta didik meskipun kejujuran itu menyakiti hati kita sendiri atau orang lain, karena kejujuran merupakan hal yang bisa menghindarkan kita dari hal-hal yang buruk yang akan terjadi jika kita tidak jujur.

\section{e. Kreatif \\ Dalam hal ini karakter kreatif juga} dimiliki oleh tokoh Rudy, adapun adegannya sebagai berikut. Ketika sedang melihat pemilik rumah yang akan dia sewa memperbaiki mesin penghangat rungan, ia dengan mudah langsung mengetahui permasalahan pada mesin tersebut. Rudy: "Nyonya, tolong ambilkan gelas berisi air beserta nampan". Pastur Gilbert: "Sudah turuti, turuti apa yang dia minta" Pemilik rumah: "Silahkan". Rudy: "Terimakasih sekali". Rudy meletakkan gelas berisi air minum diatas mesin penghangat ruangan, ia mengamatinya dan memasukkan nampan 
dibelakang mesin tersebut. (Scene 5, 08:3010:00). Berdasarkan kutipan adegan tersebut, terlihat karakter kreatif yang dimiliki oleh tokoh Rudy, Rudy sedang mencari tempat tinggal namun ketika itu tak ada yang mau memberinya tempat tinggal dengan alasan Rudy berasal dari negara yang tidak mereka ketahui, ketika ia mengunjungi sebuah rumah dan ia melihat orang tersebut sedang kesulitan memperbaiki mesin penghangat ruangan, dengan tenang Rudy mencoba membantu dan mengamati mesin itu dan kemudian tanpa ragu ia mampu mengetahui permasalah sebuah mesin penghangat ruangan dengan segelas air dan sebuah nampan. Ide yang ia miliki menunjukkan bahwa ia memang mahasiswa yang kreatif. Tanpa menunggu lama, ia berhasil memperbaiki mesin penghangat ruangan itu. Hal ini sangat penting untuk ditiru oleh peserta didik, agar semua peserta didik mampu menghasilkan sebuah ide-ide yang baru.

\section{f. Gemar Membaca}

Karakter ini dapat dilihat pada kutipan di bawah ini. Pekerja pabrik: "Hei Indonesia, kamu membaca sastra Jerman ya memangnya kamu paham?" Rudy: "Iya, memang susah. Paling susah di dunia" Pekerja pabrik: "Hei Fritz, kemarilah dengar apa yang anak ini katakan. Katanya bahasa
Jerman paling susah di dunia. Untung saja bayi kita lahir di sini”. (Scene 35, 49:5050:08). Berdasarkan kutipan di atas, dapat terlihat adegan ketika Rudy dan para pekerja pabrik sedang makan siang, disela-sela waktu istirahatnya, Rudy menyempatkan diri untuk membaca buku tentang sastra Jerman. Ia berusaha memahami setiap kata, meskipun para pekerja pabrik yang merupakan penduduk asli Jerman datang dan berusaha mengejek dan menertawakannya. Namun Rudy tetap membaca buku tersebut.

\section{g. Demokratis}

Karakter demokratis dapat dilihat pada kutipan di bawah ini. Rudy: "Sudah pertimbangkan permintaan saya, petisi saya? Kita harus punya tempat shalat yang layak" Erbakan: "Saya setuju, saya akan meminta kawan-kawan dari Turki untuk mendukungmu. Namun, kamu harus melibatkan negara saya juga". Rudy: "Kenapa, kan saya yang mengajukan". Erbakan: "Rudy, kita semua sama, Islam tidak dimiliki negaramu saja". Rudy: "Ehm, ya ayo buat nama lain yang menunjukkan kita muslim adalah satu keluarga" (Scene 59, 01:16:50-01:17:30). Berdasarkan kutipan di atas, dapat terlihat ketika Rudy dan Erbakan selesai melakasanakan salat, mereka membicarakan tentang usulan Rudy untuk membuat musala di dekat kampus 
mereka. Awalnya Rudy sedikit ragu untuk memasukkan nama negara Turki dalam rencana tersebut, namun mengingat bahwa mereka sesama muslim akhirnya Rudy menyetujui hal tersebut, ia menyadari bahwa mereka sama-sama memiliki hak untuk memiliki tempat ibadah yang layak.

\section{h. Tanggung Jawab}

Karakter tanggung jawab juga ditunjukkan oleh tokoh Rudy, berikut ini adegan yang menunjukkan karakter tersebut. Rudy terpilih menjadi kepala bidang dirgantara, namun Rudy menolak dan berbagai masalah muncul menyebabkan Rudy semakin tidak mau menjadi kepala bidang dirgantara, namun diakhir cerita tibatiba Rudy datang ke Praha dan bertemu dengan anggota PPI lainnya. Rudy:'Hey boleh saya ikut berfoto". Sugeng: "Loh mas Rudy, mas Rudy.." Semua teman-temannya kaget dan memeluk Rudy, mereka berfoto bersama-sama (Scene 95, 02:10:0002:11:00). Berdasarkan adegan di atas, terlihat Rudy yang tiba-tiba datang dalam acara seminar pembangunan di Praha karena tanggung jawabnya yang telah dipilih sebagai kepala bidang dirgantara oleh teman-temannya. Meskipun pada awalnya ia menolak untuk menjadi kepala bidang dirgantara, namun akhirnya ia tetap menghadiri acara tersebut. Karakter tersebut sangat baik untuk ditiru agar seseorang dapat mengetahui bahwa dalam keadaan apa pun kita harus tetap bertanggung jawab dengan apa yang sudah dipercayakan kepada kita.

\section{i. Cinta Tanah Air}

Berikut ini adegan dan percakapan yang menunjukkan karakter tersebut. Sumpahku! Terlentang! Djatuh! Perih! Kesal! Ibu pertiwi Engkau pegangan Dalam perdjalanan Djanji pusaka dan sakti (Scene 71, 01:36:30-01:37:10). Pada kutipan adegan di atas dapat terlihat keyakinan yang dimiliki oleh Rudy terhadap negara Indonesia. Meski dalam keadaan sakit, ia menuliskan sumpahnya di atas kertas untuk Indonesia. Ia meyakini bahwa ia mampu untuk menjadi kuat dan memperjuangkan apa yang ia cita-citakan. Kemudian pada adegan kedua yaitu Illona mengajak Rudy untuk ikut bersamanya dan meninggalkan semua mimpi-mimpinya, namun Rudy menolak hal itu karena kecintaanya terhadap negaranya Indonesia. Adegan tersebut sangat patut untuk dicontoh semua orang dapat mencintai negaranya sendiri, sehingga kita semua dapat membantu pemerintah dalam memajukan negara kita yang tercinta.

\section{Pembahasan}

Film Rudy Habibie sutradara Hanung Bramantyo memiliki nilai-nilai karakter pendidikan yaitu mengajak manusia untuk 
berbuat kebaikan dan menghindari sifat buruk sesuai dengan norma yang telah diterapkan. Demi untuk perbaikan mutu pendidikan saat ini hendaknya dikembalikan kepada penanaman keterampilan afektif, psikomotorik, emosional, spiritual, intelektual, dan bukan hanya kognitifnya saja. Selain itu perlu juga ditanamkan dalam diri siswa bahwa pembelajaran bahasa dan sastra pada dasarnya bukan hanya belajar tentang bahasa atau sastra saja melainkan seorang guru juga harus mampu membimbing dan mengajarkan pendidikan karakter. Pembinaan peserta didik untuk menjadi seseorang yang memiliki budi pekerti yang baik. Nilai-nilai pendidikan karakter dalam film Rudy Habibie sutradara Hanung Bramantyo dapat membawa nilai positif bagi peserta didik untuk menjadi pribadi yang lebih baik. Berdasarkan hasil analisis yang telah dilakukan terhadap film Rudy Habibie sutradara Hanung Bramantyo dapat ditemukan beberapa nilai pendidikan karakter, adapun nilai-nilai tersebut diantaranya nilai religius, kerja keras, peduli sosial, jujur, kreatif, gemar membaca, demokratis, tanggung jawab, dan cinta tanah air. Nilai-nilai pendidikan karakter tersebut sangat patut untuk ditiru bahkan diterapkan oleh peserta didik, karena seperti pendapat Aunillah (2011:11) pada hakikatnya pendidikan dilaksanakan bukan sekedar untuk mengejar nilai-nilai, melainkan memberikan pengarahan kepada setiap orang agar dapat bertindak dan bersikap benar sesuai dengan kaidah-kaidah dan spirit keilmuan yang dipelajari. Dengan demikian pada lingkungan pendidikan siswa dituntut bukan hanya berprestasi dalam bidang akademik saja melainkan siswa harus cerdas dan memiliki budi pekerti yang baik. Berdasarkan hasil penelitian yang menunjukkan bahwa dalam film Rudy Habibie sutradara Hanung Bramantyo mengandung nilai-nilai pendidikan karakter, hal ini merupakan salah satu langkah yang tepat bila seorang guru bahasa dan sastra di sekolah menjadikan film ini sebagai media pembelajaran sastra. Mengingat tujuan pendidikan adalah membantu peserta didik menjadi manusia yang beriman, bertaqwa, berakhlak mulia, sehat, berilmu, cakap, kreatif, adil, serta bertanggung jawab. Demi perbaikan mutu pendidikan perlu juga ditanamkan dalam diri siswa bahwa mereka harus mempunyai mental kepribadian yang baik, agar selain peserta didik itu cerdas mereka juga dapat bertindak dan bersikap benar sesuai dengan kaidah-kaidah yang dipelajari, hal ini berhubungan erat dengan tugas guru harus mampu memberikan penjelasan mengenai tujuan pendidikan dan cara bersikap yang semestinya. Penelitian ini dapat membantu siswa untuk mempelajari nilai yang terdapat dalam suatu karya sastra, serta membentuk sikap dan 
Rita Nilawijaya...

karakter seorang peserta didik untuk

Khrisna Pabichara dan Relevansinya menjadi lebih baik. Dengan adanya penelitian ini di harapkan menjadi lahan baru bagi peserta didik untuk mempelajari suatu karya sastra melalui film.

\section{SIMPULAN}

Berdasarkan hasil analisis nilai pendidikan karakter dalam film Rudy Habibie sutradara Hanung Bramantyo dapat disimpulkan bahwa, di dalam film tersebut terdapat nilai-nilai pendidikan karakter yang meliputi nilai religius, kerja keras, suka menolong, jujur, cerdas, percaya diri, tanggung jawab, nasionalis, dan berani. Relevansi nilai-nilai pendidikan karakter dalam film Rudy Habibie sutradara Hanung Bramantyo dapat dijadikan materi pembelajaran sastra yang mempelajari nilainilai dalam pementasan drama dan pendidikan karakter serta dapat membawa nilai positif bagi peserta didik.

\section{DAFTAR PUSTAKA}

Aminuddin. (2011). Pengantar Apresiasi Karya Sastra. Malang: Sinar Baru Algensindo.

Arikunto, Suharsimi. (2013). Prosedur Penelitian. Jakarta: Rineka Cipta

Aunillah, Nurla Isna. (2011). Panduan Menerapkan Pendidikan Karakter disekolah. Jogjakarta: Laksan

Dewi, Ni Luh Agustina, dkk. (2014). "Analisis Nilai-Nilai Pendidikan Karakter Novel Sepatu Dahlan Karya

Terhadap Pengajaran Pendidikan Karakter Sekolah Di Indonesia”. Jurnal Pendidikan Bahasa dan Sastra Indonesia Vol 2 No 1. Diakses tanggal 24 Februari 2017 pukul 13:20. Singaraja: Universitas Pendidikan Ganesha.

Ismawati, Esti. (2013). Pengajaran Sastra. Yogyakarta:

Kasnadi dan Sutejo. (2010). Kajian Prosa: Kiat Menyisir Dunia Prosa. Yogyakarta: Spectrum.

Kosasih. (2012). Dasar-dasar Keterampilan Bersastra. Bandung: Yrama Widya.

Mustari, Mohamad. (2014). Nilai Karakter Refleksi Untuk Pendidikan. Jakarta: Raja Grafindo Persada..

Maulana Malik Ibrahim. Samani, Muchlas,. dan Hariyanto. (2012). Konsep dan Model Pendidikan Karakter. Bandung: Remaja Rosdakarya Offset.

Nilawijaya, Rita. (2018). "Gaya Bahasa Dalam Novel Till It's Gone Karya Kezia Evi Wiadji Tehadap pembelajaran Sastra”. Jurnal Kajian Bahasa, Sastra dan Pengajaran (KIBASP) p-ISSN:2597-520X Vol.2 No.1 Juli-Desember 2018 hal 11-23).

Nilawijaya, Rita dan Inawati. (2020). "Resepsi Mahasiswa Universitas Baturaja Dalam Novel Ayat-Ayat Cinta 1 karya Habiburrahman El Shirazy Terhadap Nilai Moral Tokoh Utama". Jurrnal Online STKIP PGRI Bandar Lampung. http://jurnal.stkippgribl.ac.id/index.ph $\mathrm{p} /$ lentera/article/view/504

Nilawijaya, Rita dan Inawati. (2020). "Tinjauan Sosiologi Sastra Dalam Novel Ayah Karya Andrea Hirata Dan Implementasinya Sebagai Bahan Ajar Sastra Di SMA". Jurrnal Online Universitas Bina 
Dharma.http://journal.binadarmal.ac.i d/index.php/binabahasa/authorDashbo $\operatorname{ard} /$ submission $/ 866$

Nurgiyantoro, Burhan. (2010). Penilaian Pembelajaran Bahasa dan Sastra. Yogyakarta. BPFE.

Pradopo, Rahmat Djoko. (2009). Pengkajian Puisi. Yogyakarta: Gadjah Mada University Press.

Rusman. 2012. Model-Model Pembelajaran: Mengembangkan Profesionalisme Guru. Jakarta: PT RajaGrafindo Persada.

Pratista, Himawan. 2008. Memahami film. Yogyakarta: Homerian Pustaka.

Rahmanto, Bernardus. (2005). Metode Pengajaran Sastra. Yogyakarta: Kanisius.

Ratna, Nyoman Khuta. (2010). Teori, Metode dan Teknik Penelitian Sastra. Yogyakarta: Pustaka Pelajar.

Rohman, Saifur. (2012). Pengantar Metodologi Pengajaran Sastra. Jogjakarta: Ar Ruzz Media..

Rochmawati, Warda Putri. 2016. "Analisis Nilai-Nilai Pendidikan Karakter dalam Film The Miracle Worker". Skripsi tidak diterbitkan. Malang: Universitas Islam Negeri.

Semi, Atar. 1997. Metode Penelitian Sastra. Bandung: Angkasa.

Setiawan, Beni. (2014). Sepatu Dahlan. Jakarta: Mizan Productions.

Siswantoro. (2010). Metode Penelitian Sastra. Yogyakarta: Pustaka Pelajar. 